\title{
Inkjet technology for ceramic products. Influence of some process variables on ink penetration
}

\author{
J.L. Amorós( $(1,2)$, A. Moreno( $\left.{ }^{1,2}\right)$, E. Blasco( $\left.{ }^{1}\right)$, J.J. Pérez( $\left.{ }^{3}\right)$, S. Navarro( $\left.{ }^{3}\right)$, \\ S. Reverter $\left({ }^{3}\right)$ \\ ${ }^{1}$ Instituto de Tecnología Cerámica - Asociación de Investigación de las Industrias Cerámicas. \\ 2Department of Chemical Engineering. Universitat Jaume I, Campus Universitario Riu Sec, \\ 12006 Castellon, Spain. *encarna.blasco@itc.uji.es.
}

${ }^{3}$ Color Esmalt, S.A.

\begin{abstract}
Inkjet technology has become very popular in recent years and is nowadays widely used for decorating ceramic products. This has led to in-depth study of the operating principles and process variables involved. These notably influence the properties of the deposited ink layers, as do the physicochemical properties of the applied inks and of the glazes on which the inks are deposited. The problems associated with these factors are further heightened when inks with complex formulations designed to obtain special effects and specific surface properties are used. This study examines the characteristics of the interface that developed on applying an ink on a certain type of glaze, as well as the surface properties of the final product. The relationship of the amount of ink applied per unit area and the particle size distribution of the glaze on which it was deposited to ink penetration into the glaze layer was also investigated. The resulting microstructures were observed by SEM, while the variation of glaze layer composition with distance to the surface was determined by SEM-EDS. The results obtained were successfully correlated with the porous texture of the unfired glaze (determined by SEM and mercury porosimetry) and with unfired glaze particle size distribution.
\end{abstract}

Keywords: metallic effect, inkjet, ink penetration, glaze porous structure. 


\section{Introduction}

Digital printing is nowadays widely used for decorating ceramic products. Noble metal-free, metal-like, tile decoration was developed in the first decade of the 21 st century. These glazes are still used in traditional applications, mainly by the bell/waterfall method, which requires application of a large amount of glaze per unit surface area $\left(200-300 \mathrm{~g} / \mathrm{m}^{2}\right)$ for the above effect to develop appropriately. Studies [1][2][3][4][5][6] indicate that, in these glazes, which have a high phosphorus and iron content, during fast firing of the tiles in a typical single-firing process, surface crystallisation occurs of iron phosphates, mixed alkali and alkaline-earth phosphates, and haematite nanocrystals, which together determine the surface appearance of the fired coating.

As digital printing hardly allows such large amounts of glaze to be applied as those required to obtain the metallic effect, Color Esmalt, S.A., has developed and patented a method for obtaining a metallic effect on ceramic bases by inkjet printing [7]. The method yields a metallic effect by a superimposed application of glaze and ink with an appropriate chemical composition. The set of oxides required to obtain the metallic gloss is distributed between both applications: the iron oxide is introduced in the ink, whereas the other oxides make up the glaze on to which the ink is applied.

A previous study verified that the appearance and nature of the coating depended on the relationship between the iron oxide and phosphates concentration in the proximities of the tile surface, this depending on operating variables such as amount of ink applied per unit surface area (proportional to dots per inch (dpi)) and particle size distribution of the glaze on to which the ink was applied [8]. The role of glaze particle size on the appearance and nature of the coating surface appeared to be linked to the effect of this variable on glaze porous texture and to the effect of glaze pore structure on ink penetration (Figure 1) [9]. Indeed, the appearance of the glaze changed substantially with these variables. Thus, as the applied amount of ink (dpi) increased, surface colour shifted from brown to grey. On the other hand, colour intensity increased as the average particle size of the glaze, (D50)gl, on which the ink was applied, increased. With regard to the metallic effect, this was only observed for high values of dpi and $\left(D_{50}\right)_{\mathrm{gl}}$. 
In the present study, the ink-glaze interaction zone in the fired tile was examined to correlate the amount of ink deposited per unit area (dpi), particle size distribution of the glaze substrate, and unfired glaze pore structure with ink penetration into the glaze layer. A model was also developed, which describes ink penetration as a function of the characteristics of unfired glaze porous texture and of the amount of applied ink (dpi).

\section{Experimental}

The test glaze and engobe compositions were prepared from frit and other crystalline raw materials by wet milling. The test ink was prepared according to the appropriate technical specifications for application in DIMATIX 1024 and XAAR 1002 printheads. A standard industrial porcelain tile composition was used as ceramic base. The reference values of the process variables are summed up in Table 1.

Various experiments were conducted to determine the effect of the different process variables on ink penetrability and final coating appearance, modifying the reference conditions (Table 1). In the case of the glaze, to obtain a wide particle size distribution (PSD) range, standard glaze suspension, G1, was milled in a laboratory ball mill for different times to obtain progressively finer particle size distributions, referenced G2-G5. The particle size distributions of the glaze and ink suspensions were determined by laser diffraction (Mastersizer 2000, Malvern Instruments Ltd, UK) using Fraunhofer and Mie theory, respectively, to interpret the light scattering signal collected by the detectors. For the ink, the calculation was made considering a refractive index of 3.1 for hematite, and an absorption coefficient value of 4 . The results are detailed in Table 2.

The ink was applied by inkjet technology with different resolutions, from 400 to $1200 \mathrm{dpi}$, to obtain a different weight per unit surface area. Thermal treatment matched the standard porcelain tile firing cycle used in industrial practice. Peak firing temperature was modified in the G4 series of experiments to determine the influence of this variable.

Surface and transverse microstructural characterisation was performed by scanning electron microscopy (SEM) under high-vacuum conditions. Test piece cross-sections were prepared in order to determine ink penetration depth and layer interactions. The composition profiles were 
determined by taking three energy-dispersive X-ray (EDS) spectra of 5x250 $\mu \mathrm{m}$ at each depth and averaging the results. The major inorganic component of the ink was $\mathrm{Fe}_{2} \mathrm{O}_{3}$ and, as the glaze contained no $\mathrm{Fe}_{2} \mathrm{O}_{3}$, ink penetration was monitored by determining the $\mathrm{Fe}_{2} \mathrm{O}_{3}$ mole

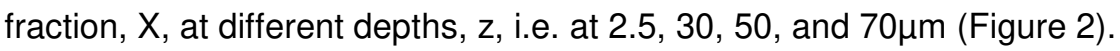

To determine the $\mathrm{Fe}_{2} \mathrm{O}_{3}$ surface mole fraction, $\mathrm{X}_{0}, 10 \mathrm{EDS}$ analyses of each sample surface were performed on areas of $250 \times 250 \mu \mathrm{m}$, selected at random, averaging the results (Figure 3 ). Note that, in surface analysis, the electron beam penetration, albeit reduced (of the order of 1 $\mu \mathrm{m})$, was considerable. The resulting analysis did not therefore correspond exactly to the irradiated surface but to a very thin layer. Nevertheless, for the sake of simplicity, the term surface analysis will be used hereafter for what was in fact analysis of a thin surface layer.

To characterise the resulting porous texture for each glaze particle size, cylindrical test pieces about $2 \mathrm{~cm}$ high and $2 \mathrm{~cm}$ in diameter of glazes G1-G5 were prepared by slip casting. Mercury porosimetry was used to determine test piece intrusion pore size distribution (PSD). Test piece microstructure was observed by scanning electron microscopy (SEM).

\section{Results and discussion}

\subsection{Influence of some process variables on ink penetration}

i) Peak firing temperature

The penetration curve of $\mathrm{Fe}_{2} \mathrm{O}_{3}$ into glaze $\mathrm{G} 4$, on industrial tiles fired at three peak temperatures, is plotted in Figure 4. It shows that the effect of this variable on ink penetration was practically negligible. The point scatter observed for high $\mathrm{Fe}_{2} \mathrm{O}_{3}$ contents was similar to the measurement error. These results indicate that $\mathrm{Fe}_{2} \mathrm{O}_{3}$ penetration due to diffusion into the glass matrix of the glaze was virtually negligible and/or $\mathrm{Fe}_{2} \mathrm{O}_{3}$ penetration only increased very slightly with peak temperature. $\mathrm{Fe}_{2} \mathrm{O}_{3}$ penetration into the glaze therefore depended solely on ink suction by the unfired glaze.

ii) Effect of deposited amount of ink 
As the amount of applied ink (dpi) increased, the $\mathrm{Fe}_{2} \mathrm{O}_{3}$ concentration, $\mathrm{X}$, rose at the same distance to the surface, $z$, (Figure 5). However, the maximum penetration reached did not appear to depend on the amount of applied ink.

iii) Effect of glaze particle size distribution

As average glaze particle size and distribution width decreased, ink penetration also decreased, while the iron concentration increased in the uppermost layers (Figure 6). This behaviour stemmed from the increasing ability of the glaze to suck up ink as glaze porosity and average pore size and connectivity rose, which all increased when average glaze particle size increased.

The penetration curves corresponding to glaze G3, G4, and G5 particle sizes are plotted in Figure 6. The results corresponding to the coarsest glaze particle distributions (G1 and $G 2$ ) coincided with those of G3.

\subsection{Model describing ink penetration}

Nanoparticle penetration into unsaturated porous media by capillary suction has drawn little attention [10][11][12][13], unlike nanoparticle transport in saturated porous media, as compiled by Babakhani et al. [14]. They reviewed the experimental data obtained by numerous researchers (compiling more than 160 references), highlighting the influence that the properties of the liquid and porous medium, including the interactions of these media, had on nanoparticle retention. Despite the notable importance of having a nanoparticle concentration profile inside a porous medium in which a suspension has penetrated by capillary suction, no paper was found on this topic in inkjet printing technology (on paper, fabric, or ceramic substrate). In fact, as already noted in the introduction, surface appearance after inkjet application on a ceramic substrate differs highly as a function of operating conditions, which in turn determine pigment nanoparticle penetration.

\section{i) Development}

In view of the above results, a model was developed based on the following assumptions: 
During ink suction by the unfired glaze, colloidal pigment particles are adsorbed [13] in the finest pores or retained in dead-end pores. This causes the $\mathrm{Fe}_{2} \mathrm{O}_{3}$ mole fraction, $\mathrm{X}$, to decrease with distance to the surface, $d x / d z<0$ (Figure 2).

$\mathrm{Fe}_{2} \mathrm{O}_{3}$ diffusion into the glaze during firing relative to ink penetration by suction is negligible (Figure 4).

Consequently, the effect of the operating variables on the penetration curves in the fired glaze, $X$ vs $z$, are due to their influence on the suction process in the unfired glaze.

In view of the shape of these curves, $X=f(z)$, taking into account the foregoing assumptions, $a$ simple equation was considered that expressed the $\mathrm{Fe}_{2} \mathrm{O}_{3}$ concentration gradient, $d \mathrm{X} / \mathrm{dz}$, with depth, $\mathbf{z}$ :

$$
\frac{d X}{d z}=-(d p i) k X z^{-n}
$$

According to this model, the gradient of the $\mathrm{Fe}_{2} \mathrm{O}_{3}$ mole fraction, which also expressed the point pigment particle retention in the glaze, $\mathrm{dX} / \mathrm{dz}$, at depth $\mathrm{z}$, was directly proportional to the applied amount of ink, dpi, to the $\mathrm{Fe}_{2} \mathrm{O}_{3}$ mole fraction, $\mathrm{X}$, at depth $\mathrm{z}$, and to a retention coefficient, $\mathrm{k}$, dependent on unfired glaze porous texture and pigment particle size [13][14]. The $z^{-n}$ function assumes that some pores become dead-end near the surface, thus restricting mobile pigment particles to continuous larger-pore networks. The number of dead-end pores is assumed to decrease with increasing $z$ because, as $z$ increases, ink tends to flow increasingly through the larger pores [15] [16].

Separating variables in Eq. 1 and integrating yield:

$$
\ln X=\frac{-(d p i) k X z^{(1-n)}}{(1-n)}+C
$$

Observation of the $X$ spatial distribution profile, $X=f(z)$, making the above assumptions and applying the boundary condition in Eq. 2 (at the glaze surface, $\mathrm{z}=0$ and the $\mathrm{Fe}_{2} \mathrm{O}_{3}$ mole fraction is $\mathrm{X}=\mathrm{X}_{0}$ ), yields: 
where: $m=1-n$ and $K=(d p i) k /(1-n)$.

ii) Verification

The experimental results were fitted to the developed model (Figure 5 and Figure 6 ) with $n=0.6$. The effect of the deposited amount of ink on the $\mathrm{Fe}_{2} \mathrm{O}_{3}$ surface mole fraction, $\mathrm{X}_{0}$, and on the retention coefficient, $\mathrm{k}$, are shown in Figure 7 . The figure shows that the experimental data for $X_{0}$ coincided with the values calculated using the model $\left(X_{0 \text { cal }} \approx X_{0 \text { exp }}\right)$. The influence of the deposited amount of ink, dpi, on $\mathrm{X}_{0}$ was considerable, it being possible to describe this effect by a power equation. It may also be observed, as had been assumed on developing the model, that the effect of dpi on the retention coefficient, $k$, was practically negligible.

In order to determine the effect of glaze particle size distribution on model parameters, $\mathrm{X}_{0}$ and $\mathrm{k}$, first, the average glaze particle diameter, ( $\left.D_{50}\right)_{g l}$, was selected (Figure 8). The figure shows that the experimental data for the $\mathrm{Fe}_{2} \mathrm{O}_{3}$ surface mole fraction, $\mathrm{X}_{0}$, and the values calculated with the model practically coincided, as occurred in Figure 7. It may further be observed that both the retention coefficient, $k$, and $X_{0}$ decreased considerably as average glaze particle size, $\left(D_{50}\right)_{g l}$, increased. The effect of this parameter on $\mathrm{X}_{0}$ and on $\mathrm{k}$ was described very well by the corresponding power relationships (Figure 8). This behaviour was related to the effect of glaze particle size distribution on the porous texture of the consolidated layer and hence on ink penetration into the glaze.

\subsection{Relationship between unfired glaze porous structure and ink penetration}

In order to relate the porous texture of the consolidated glaze layer to its particle size distribution, obtained on modifying test glaze degree of milling (Table 2), the slip-cast test pieces were observed by SEM. By way of example, a SEM micrograph of an unfired test piece of glazes G1-G5 is shown in Figure 9. Increasing the degree of glaze milling and hence reducing average particle size and particle size distribution width was observed to lead to a considerable decrease in coarsest pore size and volume. This was confirmed by mercury 
porosimetry (Figure 10). Indeed, as test glaze degree of milling increased, average pore intrusion diameter and pore size distribution width decreased. However, the smallest pore volume and size were hardly modified, particularly for the G1, G2, and G3 particle sizes, whose pore size distribution curve sections for $d_{\text {intrusion }}<0.1 \mu \mathrm{m}$ coincided.

On the other hand, the tortuosity of either geometric or hydraulic porous media [17] must increase as average particle size, $\left(D_{50}\right)_{\mathrm{gl}}$, and particle size distribution width decrease, as may be deduced from Figure 9. Indeed, the length of the path that the fluid must follow through the particle bed increased from $\mathrm{G} 1$ to $\mathrm{G} 5$. In addition, average pore size, $\left(\mathrm{d}_{50}\right)_{\text {pore, }}$ determined by mercury porosimetry, decreased from $\mathrm{G} 1$ to $\mathrm{G} 5$, which must lead to an exponential increase in pore tortuosity according to the literature [18] [19] [20].

Two parameters were selected, based on ink pigment particle size and glaze pore structure, determined by mercury porosimetry: i) glaze porosity, $\varepsilon^{*}$, whose pore size was equal to or larger than average ink pigment particle diameter, $\left(D_{50}\right)_{\text {ink }}=0.29 \mu \mathrm{m}$, and ii) ratio of average pore diameter to average ink pigment particle diameter, $\left(d_{50}\right)_{\text {pore }} /\left(D_{50}\right)_{\text {ink, }}$ also used by Bradford et al. [16]. Both parameters were verified to be clearly related to average glaze particle size (Figure 11). Pore tortuosity must follow the same trend as $\left(d_{50}\right)_{\text {pore }} /\left(D_{50}\right)_{\text {ink, }}$ as average pore size, $\left(d_{50}\right)_{\text {pore }}$, and average glaze size, $\left(D_{50}\right)_{g l}$, were directly related, as Figure 10 shows. On plotting model parameters, $\mathrm{X}_{0}$ and $\mathrm{k}$, versus $\varepsilon^{*}$ (Figure 12 ), the $\mathrm{Fe}_{2} \mathrm{O}_{3}$ surface mole fraction, $\mathrm{X}_{0}$, and the retention coefficient, $\mathrm{k}$, decreased exponentially as the volume fraction of pores larger than those of ink particle size, $\varepsilon^{*}$, increased.

Operating analogously but using the ratio of average pore diameter to average ink pigment particle diameter, $\left(d_{50}\right)_{\text {pore }} /\left(D_{50}\right)_{\text {ink, }}$ as characteristic parameter of glaze pore structure relative to ink particle size, yielded Figure 13. A good relationship may be observed between $\left(d_{50}\right)_{\text {pore }} /\left(D_{50}\right)_{\text {ink }}$ and the $\mathrm{Fe}_{2} \mathrm{O}_{3}$ surface mole fraction, $\mathrm{X}_{0}$, and retention coefficient, $\mathrm{k}$. The values for $\left(d_{50}\right)_{\text {pore }} /\left(D_{50}\right)_{\text {ink }}$ were slightly lower than 1 . That is, when average pore size was smaller than average ink particle size, $\mathrm{k}$ and $\mathrm{X}_{0}$ increased considerably as structural parameter $\left(d_{50}\right)_{\text {pore }} /\left(D_{50}\right)_{\text {ink }}$ decreased.

\section{Conclusions}


The study examined the effect of different operating variables on ink penetration into a glaze, using EDS to determine the variation of the $\mathrm{Fe}_{2} \mathrm{O}_{3}$ mole fraction with distance to the glaze surface in the fired test pieces.

Ink distribution in the fired glaze layer was found to depend solely on ink penetration into the unfired glaze layer.

A simple model was developed that satisfactorily describes ink penetration into the glaze layer and the quantity of ink retained in the glaze surface as a function of the applied amount of ink, $\mathrm{dpi}$, and of an ink retention coefficient, $\mathrm{k}$, the latter depending solely on the texture of the unfired glaze layer.

Very good relationships were obtained that describe the effect of glaze particle size distribution, glaze pore size larger than ink pigment particle size, and the ratio: average pore size/average ink pigment particle size on the ink retention coefficient and on the amount of ink retained in the glaze surface.

\section{References}

1. Rincón J.M. Características especiales de los sistemas vítreos aplicables a la producción de nuevos esmaltes cerámicos. In: Nuevos productos y tecnologías de esmaltes y pigmentos cerámicos. Su fabricación y utilización. Castellón: Eds. J. Ma․ Rincón, J. Carda y J. Alarcón. Co-Eds: Faenza Editrice Ibérica y Sociedad Española de Cerámica y Vidrio, 1992; p. 13-38.

2. Cabrera M. J., Montins V., Foó A., Balfagon P. Obtención de esmaltes de aspecto metálico en baldosas fabricadas por monocción. Paper presented at: Qualicer 2006. Proceedings of IXth World Congress on Ceramic Tile Quality; 2006 Feb 12-15; Castellón: 2006. p. P. BC $261-273$.

3. Pérez J., Reverter S., Navarro E. Obtención de efecto metálico de gran calidad mediante el empleo de pigmentos sintéticos. Paper presented at: Qualicer 2008. Proceedings of Xth World Congress on Ceramic Tile Quality; 2008 Feb 10-13; Castellón: 2008. p. P. BC $123-139$.

4. Siligardi C., Montorsi M., Venturelli E. Caratterizzazione di smalti ferro-metallici apiombici. Ceramica Informazione. 2008; 464: 716-721. 
5. Casasola R., Rincón J. M., Romero M. Glass-ceramic glazes for ceramic tiles: a review. Journal of Materials Sicence. 2012; 47: 553-582.

6. Pekkan K., Tasçi E., Uz V. Production of metallic glazes and their industrial applications. Journal of Australian Ceramic Society. 2015; 51(1): 110-115.

7. SAMCA - Sociedad Anónima Minera Catalano-Aragonesa. Procedimiento de obtención de aspecto metálico sobre bases cerámicas por inyección. Spain patent ES 2396 399. 2013 Feb 21.

8. Moreno A., Amorós J. L., Blasco E., Pérez J. J., Navarro S., Reverter S. Study of interface and surface properties in multilayer ceramic systems. Paper presented at: Qualicer 2016. Proceedings of XIVth World Congress on Ceramic Tile Quality; 2016 Feb 8-9; Castellón: 2016. p. www.qualicer.org.

9. Amorós J. L., Moreno A., Blasco E., et al. Aplicación ink-jet. Influencia de algunas variables de operación sobre la penetración de la tinta. Poster session presented at: LV SECV 2016. Proceedings of LVth National Congress of the Spanish Ceramic and Glass Society; 2016 Oct 5-7; Seville: 2016.

10. Gao B., Steenhuis T.S., Zevi Y., et al. Capillary retention of colloids in unsaturated porous media. Water resources research. 2008; 44: 1-7.

11. Steenhuis T.S., Dathe A., Zevi Y., et al. Biocolloid retention in partially saturated soils. Biologia (Bratisl). 2006; 61(19): S229-S233.

12. Flury M., Aramrak S. Role of air-water interfaces in colloid transport in porous media: A review. Water resources research. 2017; 53: 5247-5275.

13. Kuijpers C. J., Huinink H. P., Tomozeiu N., et al. Nano-particle dynamics during capillary suction. Journal of colloid and interface science. 2018; 521: 69-80.

14. Babakhani P., Bridge J., Doong R., et al. Parameterization and prediction of nanoparticle transport in porous media: A reanalysis using artificial neural network. Water resources research. 2017; 53: 1-22.

15.Bradford S.A., Simunek J., Bettahar M., et al. Modeling colloid attachment, straining, and exclusion in Saturated Porous Media. Environmental science and technology. 2003; 37(10): 2242-2250. 
16. Bradford S.A., Yates S.R., Bettahar M. Physical factors affecting the transport and fate of colloids in saturated porous media. Water resources research. 2002; 38(12): 1237.

17. Ghanbarian B., Hunt A.G., Ewing R.P., Sahimi M. Tortuosity in porous media: A critical review. Soil science society of America journal. 2012; 77: 1461-1477.

18. Armatas G.S. Determination of the effects of the pore size distribution and pore connectivity distribution on the pore tortuosity and diffusive transport in model porous networks. Chemical Engineering Science. 2006; 61: 4662-4675.

19. Latour L.L., Kleinberg R.L., Mitra P.P., et al. Pore-size distributions and tortuosity in heterogeneous porous media. Journal of magnetic resonance A. 1995; 112: 83-91.

20. Vervoort, R.W., Cattle S.R. Linking hydraulic conductivity and tortuosity parameters to pore space geometry and pore-size distribution. Journal of hydrology. 2003; 272: 36-49. 
Figure 1. Notable effect of the amount of ink deposited per unit surface area (dpi) and of glaze average particle size $\left(D_{50}\right)_{g l}$ on fired tile surface finish. 
Figure 2. $\mathrm{Fe}_{2} \mathrm{O}_{3}$ mole fraction, $\mathrm{X}$, at different depths, $\mathrm{z}$. 
Figure 3. Determination of $\mathrm{Fe}_{2} \mathrm{O}_{3}$ surface mole fraction, $\mathrm{X}_{0}$. 
Figure 4. Effect of peak firing temperature on $\mathrm{Fe}_{2} \mathrm{O}_{3}$ penetration, $\mathrm{X}$ vs $\mathrm{z}$, for glaze $\mathrm{G} 4$ (dpi=600). 
Figure 5. Effect of deposited amount of ink on ink penetration, $X$ vs $z$. Peak firing temperature $1200^{\circ} \mathrm{C}$. Glaze G4. The continuous curves represent the fit of the experimental data to the model (Eq. 3). 
Figure 6. Effect of glaze particle size distribution on ink penetration curves, $X$ vs z. Peak firing temperature $1200^{\circ} \mathrm{C} . \mathrm{Dpi}=600$. Glazes G3, G4, and G5. The continuous curves represent the fit of the experimental data to the model (Eq. 3). 
Figure 7. Effect of the deposited amount of ink, dpi, on the $\mathrm{Fe}_{2} \mathrm{O}_{3}$ surface mole fraction, $\mathrm{X}_{0}$, and on the retention coefficient, $k$. 
Figure 8. Effect of average glaze particle diameter, $\left(D_{50}\right)_{g l}$, on $\mathrm{Fe}_{2} \mathrm{O}_{3}$ surface mole fraction, $\mathrm{X}_{0}$, and on the retention coefficient, $\mathrm{k}$. 
Figure 9. SEM micrographs of unfired glaze test pieces obtained by slip casting from glaze G1G5 particle size distributions. 
Figure 10. Unfired glaze pore size distributions determined by mercury porosimetry. 
Figure 11. Evolution of glaze pores whose pore diameter was equal to or larger than average ink pigment particle diameter, $\varepsilon^{\star}$, and ratio of average pore diameter to average ink pigment particle diameter, $\left(d_{50}\right)_{\text {pore }} /\left(D_{50}\right)_{\text {ink, }}$ with average glaze particle diameter, $\left(D_{50}\right)_{g l}$. 
Figure 12. Effect of glaze pores whose pore diameter was equal to or larger than average ink pigment particle diameter, $\varepsilon^{*}$, on the $\mathrm{Fe}_{2} \mathrm{O}_{3}$ surface mole fraction, $\mathrm{X}_{0}$, and on the retention coefficient, $\mathrm{k}$. 
Figure 13. Effect of the ratio of average pore diameter to average ink pigment particle diameter, $\left(d_{50}\right)_{\text {pore }} /\left(D_{50}\right)_{\text {ink, }}$, on the $\mathrm{Fe}_{2} \mathrm{O}_{3}$ surface mole fraction, $\mathrm{X}_{0}$, and on the retention coefficient, $\mathrm{k}$. 
Table 1. Reference values of the process variables.

\begin{tabular}{|c|c|c|c|c|c|c|}
\hline \multirow[t]{2}{*}{ Ref. } & \multicolumn{2}{|c|}{ Glaze PSD } & \multirow{2}{*}{$\begin{array}{l}\text { Glaze layer } \\
\text { thickness }\end{array}$} & \multicolumn{2}{|c|}{ Coating factors } & \multirow{2}{*}{$\begin{array}{l}\text { Thermal cycle } \\
\text { Porcelain tile }\end{array}$} \\
\hline & $\mathrm{D}_{50}(\mu \mathrm{m})$ & $\mathrm{D}_{90}(\mu \mathrm{m})$ & & $\begin{array}{l}\text { Resolution } \\
\text { (dpi) }\end{array}$ & $\begin{array}{l}\text { Weight } \\
\left(\mathrm{g} / \mathrm{m}^{2}\right)\end{array}$ & \\
\hline G1 & 9.3 & 38.6 & 300 & 800 & 21.6 & $1200^{\circ} \mathrm{C}$ \\
\hline
\end{tabular}


Table 2. Glaze and ink particle size distributions (PSD) used.

\begin{tabular}{|l|l|l|l|l|}
\hline Glaze & $D_{50}(\mu \mathrm{m})$ & $D_{90}(\mu \mathrm{m})$ & $D_{99.5}(\mu \mathrm{m})$ & Residue 60 $\mu \mathrm{m}(\mathrm{wt} \%)$ \\
\hline G1 & 9.3 & 38.6 & 91.8 & 3 \\
\hline G2 & 8.0 & 32.6 & 83.6 & 0.5 \\
\hline G3 & 7.3 & 28.9 & 63.8 & $<<0.5$ \\
\hline G4 & 4.9 & 18.9 & 35.6 & $<<0.5$ \\
\hline G5 & 3.3 & 13.3 & 26.2 & $<<0.5$ \\
\hline Ink & 0.29 & 0.54 & 0.80 & 0 \\
\hline
\end{tabular}

